\title{
AN ECO-EPIDEMIOLOGICAL MODEL IN TWO COMPETING SPECIES
}

\author{
Mats Gyllenberg, Xiaoli LiU And Ping Yan
}

\begin{abstract}
The population sizes of species are affected not only by ecological interactions, such as predation and competition, but also by infectious diseases. In this paper, we propose a model combining disease and competition, and try to understand how the disease affects the two competing species. We assume that only one of the species is susceptible to an SI type disease with mass action incidence, and that infected individuals do not reproduce but suffer additional disease induced death. We further assume that infection does not reduce the competitive ability of infectives. We show that if species 1 is a superior competitor without disease, then infection of species 1 can enable an inferior competitor to coexist, either as a stable equilibrium or as a limit cycle. If in the absence of the disease, the two species coexist, then the introduction of the disease is partially determined by the basic reproduction number. If the basic reproduction number is larger than 1 , then our system is uniformly persistent and the unique coexisting endemic disease equilibrium is globally stable under certain conditions. Meanwhile, if species 1 is an inferior competitor without disease, then infection of species 1 can not change the outcomes under certain conditions.
\end{abstract}

Mathematics subject classification (2010): 34D23, 92D30, 92D40.

Keywords and phrases: disease-competition, Hopf bifurcation, limit cycle, global stability.

\section{REFERENCES}

[1] R. M. ANDERSON, R. M. MAY, The invasion, persistence and spread of infectious diseases within animal and plant communities, Phil. Trans. Roy. Soc. London B., 314 (1986), 553-570.

[2] M. Begon, R. G. Bowers, N. Kadianakis, D. E. Hodgkinson, Disease and community structure: The importance of host self-regulation in a host host-pathogen model, The American Society of Naturalists, 139 (1992), 1131-1150.

[3] O. Diekmann, J. A. P. Heesterbeek, J. A. J. Metz, On the definition and the computation of the basic reproduction ratio in models for infectious diseases in heterogeneous populations, J. Math. Biol., 28 (1990), 365-382.

[4] O. Diekmann, J. A. P. Heesterbeek, Mathematical Epidemiology of Infectious Diseases: Model Building, Analysis and Interpretation (Mathematical and Computational Biology), John Wiley \& Son, 2000.

[5] P. van den Driessche, M. L. Zeeman, Disease Induced Oscillations between Two Competing Species, SIAM J. Applied Dynamical Systems, 3 (2004), 601-619.

[6] J. V. Greenman, P. J. Hudson, Host exclusion and coexistence in apparent and direct competition: An application of bifurcation theory, Theor. Pop. Biol., 56 (1999), 48-64.

[7] J. K. Hale, P. Waltman, Persistence in infinite-dimensional systems, SIAM J. Math. Anal., 20 (1989), 388-395.

[8] L. Han, A. Pugliese, Endemics in two competing species, Nonlinear Analysis: Real World Application, 10 (2009), 723-744.

[9] M. W. HIRSCH, Systems of differential equations that are competitive or cooperative. III: Competing species, Nonlinearity, 1 (1988), 51-71.

[10] J. Hofbauer, K. Sigmund, Evolutionary Games and Population Dynamics, Cambridge University Press, Cambridge, UK, 1998.

[11] R. D. Holt, J. PickeRIng, Infectious disease and species coexistence: A model of Lotka-Volterra form, The American Naturalist, 126 (1985), 196-211. 
[12] Yu. A. KuZnetsov, Elements of Applied Bifurcation Theory, 3rd ed. Applied Mathematical Sciences 112, Springer-Verlag, New York, 2004.

[13] M. Y. Li, J. S. MULDOWNEY, A geometric approach to the global stability problems, SIAM J. Math. Anal., 27 (1996), 1070-1083.

[14] J. D. Murray, Mathematical Biology, Biomath. 19, Springer-Verlag, New York, 1993.

[15] Roberto A. SAenz, Herbert W. Hethcote, competing species models with an infectious disease, Math. Biosci and engineering, 3 (2006), 219-235.

[16] E. Venturino, The effects of diseases on competing species, Math. Biosci., 174 (2001), 111-131.

[17] M. L. ZeEman, Hopf bifurcations in competitive three dimensional Lotka-Volterra systems, Dyn. Stab. Syst., 8 (1993), 189-217.

[18] Z.F. Zhang, ET AL., Qualitative Theory of Ordinary Differential Equations, Transl. Math. Monogr., Vol. 101, Amer. Math. Soc., Providence, 1992. 